\title{
CXCL12 inhibits expression of the NMDA receptor's NR2B subunit through a histone deacetylase- dependent pathway contributing to neuronal survival
}

\author{
J Nicolai ${ }^{1}$, S Burbassi ${ }^{1}$, J Rubin ${ }^{2}$ and 0 Meucci ${ }^{*, 1,3}$
}

Homeostatic chemokines, such as CXCL12, can affect neuronal activity by the regulation of inhibitory and excitatory neurotransmission, but the mechanisms involved are still undefined. Our previous studies have shown that CXCL12 protects cortical neurons from excitotoxicity by promoting the function of the gene-repressor protein $\mathrm{Rb}$, which is involved in the recruitment of chromatin modifiers (such as histone deacetylases (HDACs)) to gene promoters. In neurons, Rb controls activitydependent genes essential to neuronal plasticity and survival, such as the $N$-methyl-D-aspartic acid (NMDA) receptor's subunit NR2B, the expression of which in the tetrameric ion channel largely affects calcium signaling by glutamate. In this study, we report that CXCL12 differentially modulates intracellular responses after stimulation of synaptic and extrasynaptic NMDA receptors, by a specific regulation of the NR2B gene that involves HDACs. Our results show that CXCL12 selectively inhibits NR2B expression in vitro and in vivo altering NMDA-induced calcium responses associated with neuronal death, while promoting prosurvival pathways that depend on stimulation of synaptic receptors. Along with previous studies, these findings underline the role of CXCL12/CXCR4 in the regulation of crucial components of glutamatergic transmission. These novel effects of CXCL12 may be involved in the physiological function of the chemokine in both developing and mature brains.

Cell Death and Disease (2010) 1, e33; doi:10.1038/cddis.2010.10; published online 1 April 2010

Subject Category: Neuroscience

This is an open-access article distributed under the terms of the Creative Commons Attribution License, which permits distribution and reproduction in any medium, provided the original author and source are credited. This license does not permit commercial exploitation without specific permission.

Chronic neurodegenerative and neuroinflammatory conditions share common characteristics of neuronal dysfunction and cell death involving energy failure and excessive extracellular excitatory neurotransmitters. ${ }^{1,2}$ Increased concentrations of excitatory neurotransmitters can result in the overstimulation of membrane receptors leading to high intracellular calcium levels, a hallmark of excitotoxicity. ${ }^{3}$ Glutamate, the primary excitatory neurotransmitter, activates various metabotropic as well as ionotropic receptors, including the $\alpha$-amino-3-hydroxyl5-methyl-4-isoxazole-propionate (AMPA), Kainate, and $\mathrm{N}$-methyl-D-aspartic acid (NMDA) receptors, all of which are involved in and are required for physiological synaptic transmission. ${ }^{4}$ However, overactivation of these receptors may contribute to neurotoxicity in pathological conditions because of inappropriate activation of downstream signaling pathways. Of these excitatory receptors, NMDA receptors have a large role in excitotoxic cell death mostly due to their high calcium conductance and low rate of desensitization. ${ }^{5,6}$

NMDA receptors are heteromeric ligand-gated ion channels composed of two obligatory NR1 subunits, and two regulatory subunits (NR2A-D or NR3 A-B). ${ }^{7}$ The functional properties of the receptor depend on the subunit combination, which regulates synaptic maturation, neuronal plasticity, and survival. Expression of the regulatory subunits is developmentally and spatially regulated and influences the channel kinetics. ${ }^{8}$ Several studies have indicated that in mature neurons, NR2B-containing receptors are predominantly, although not exclusively, located extrasynaptically ${ }^{9,10}$ and that calcium influx depends on relative NR2B expression, as NR2B confers a slower decay time to the receptor. ${ }^{11}$ Neurons respond differently depending on the characteristics of calcium changes, including the magnitude of calcium rise, spatial and temporal properties, and the channel initiating calcium responses. ${ }^{12}$ Therefore, NMDA receptors located at synaptic or extrasynaptic sites may have different effects on synaptic plasticity and cellular signaling pathways. ${ }^{13,14}$ Although neuronal survival is dependent on synaptic NMDA activity, excessive excitatory neurotransmitter release activates extrasynaptic receptors, which can be neurotoxic. ${ }^{11,15}$ Understanding the dual nature of NMDA receptor function could allow for

\footnotetext{
${ }^{1}$ Department of Pharmacology and Physiology, Drexel University College of Medicine, Philadelphia, PA, USA; ${ }^{2}$ Department of Pediatrics, Washington University School of Medicine, St. Louis, MO, USA and ${ }^{3}$ Department of Microbiology and Immunology, Drexel University College of Medicine, Philadelphia, PA, USA

${ }^{*}$ Corresponding author: O Meucci, Department of Pharmacology and Physiology, Drexel University College of Medicine, 245 North 15th Street, Philadelphia, PA 19102, USA. Tel: + 215762 2597; Fax: + 215762 2299; E-mail: omeucci@drexelmed.edu

Keywords: chemokine; neuron; CXCR4; cell death; calcium

Abbreviations: NMDA, N-methyl-D-aspartic acid; NR2B, NMDA receptor 2B; NR2A, NMDA receptor 2A; Rb, retinoblastoma protein; [Ca $\left.{ }^{2+}\right]_{i}$, intracellular calcium levels; $\mathrm{KCl}$, potassium chloride; CREST, calcium-responsive transactivation; HDAC, histone deacetylase; TSA, Trichostatin A; GABA, $\gamma$-aminobutyric acid; ERK, extracellular-regulated kinase; IPBS, phosphate-buffered saline

Received 01.2.10; revised 12.2.10; accepted 18.2.10; Edited by RA Knight
} 
therapeutic targeting of specific prodeath signals, which if identified and successfully blocked might have a therapeutic effect with little impact on normal synaptic function.

Aside from their established role in immune system functioning, the chemokine CXCL12 and its receptor CXCR4 (both constitutively expressed in the developing and adult brains) have been implicated in neuronal survival in vitro and in vivo. ${ }^{16}$ Recent studies have also suggested that this chemokine may have important roles in both excitatory and inhibitory neurotransmission. ${ }^{17,18}$ Our previous research ${ }^{19,20}$ indicates that CXCL12 rescues neurons exposed to excitotoxic insults by supporting the function of the retinoblastoma protein $(\mathrm{Rb})$, which is known to recruit transcriptional repressors such as histone deacetylase (HDAC) to specific promoters, including the promoter of the NR2B gene. ${ }^{21}$ Thus, we hypothesized that $\mathrm{CXCL12}$ may regulate the NMDA receptor by modulating NR2B levels in the brain. The results presented herein show that CXCL12 reduces NR2B expression both in vitro and in vivo and differentially affects neuronal signaling triggered by selective stimulation of synaptic or extrasynaptic NMDA receptors. This novel action of CXCL12 is not only consistent with a critical role of the CXCL12/CXCR4 axis in neuroprotection, but further expands the potential of CXCL12 as a modulator of synaptic plasticity in the context of epigenetic mechanisms.

\section{Results}

CXCL12 pretreatment induces long-term cellular changes that protect cultured neurons from subsequent NMDA-induced neurotoxicity. We have previously shown that CXCL12/CXCR4 positively regulates the retinoblastoma protein $R b$ in neurons, thus inhibiting NMDA-induced neurotoxicity. ${ }^{19}$ To further characterize the mechanisms involved in CXCL12-mediated neuroprotection, we examined whether pre-exposure of neuronal cultures to CXCL12 protects neurons from a subsequent NMDA stimulus. To this end, rat cortical neurons were incubated with vehicle or CXCL12 (20 nM) for $24 \mathrm{~h}$. After removing the CXCL12-containing (or control) media, neurons were transiently exposed to toxic concentrations of NMDA $(100 \mu \mathrm{M}$ for

Figure $1 \mathrm{CXCL12}$ pretreatment prevents neuronal death and decreases NMDA-induced intracellular calcium rise. CXCL12 $(20 \mathrm{nM})$ or vehicle was added to the culture media of rat cortical neurons $24 \mathrm{~h}$ before NMDA exposure, as described in the 'Materials and methods' and 'Results' sections. (a) Cell survival was assayed $24 \mathrm{~h}$ after NMDA treatment $(20 \mathrm{~min}, 100 \mu \mathrm{M})$. The graph shows NMDA-induced cell death in cultures pretreated with vehicle, or CXCL12 (in the presence or absence of the CXCR4 antagonist AMD3100); basal cell death in untreated neurons was $11.15 \pm 1.42$, (mean \pm S.E.M., $n=3$ ), as indicated by the line in the graph. AMD3100 $(100 \mathrm{ng} / \mathrm{ml})$ was added to the cultures $20 \mathrm{~min}$ before $\mathrm{CXCL} 12\left({ }^{*} P<0.01\right.$, ANOVA; CXCL12-treated significantly lower than vehicle and AMD3100+ CXCL12). (b) CXCL12 pretreatment decreases calcium response stimulated by NMDA $(100 \mu \mathrm{M}, 90 \mathrm{~s})$. The effect was blocked by cotreatment with AMD3100 $(100 \mathrm{ng} / \mathrm{ml})$. Traces show average ratios (mean \pm S.E.M.) from at least 60 cells per treatment analyzed individually ( ${ }^{*} P<0.05$, ANOVA; CXCL12 significantly lower than vehicle and AMD3100 + CXCL12). (c) Similar responses are observed with lower NMDA concentrations $(50 \mu \mathrm{M})$. (d) NMDA-induced $(50 \mu \mathrm{M})$ calcium rise in the absence (first and second peak) and presence (third peak) of the L-type calcium channel inhibitor nifedipine $(5 \mu \mathrm{M})$
$20 \mathrm{~min}$ ) and then returned to their regular culture media (i.e., without CXCL12). Delayed NMDA-induced neurotoxicity was evaluated the next day as reported previously. ${ }^{19,20,22}$ The results of these studies (Figure 1a) show that the extent of neuronal cell death caused by NMDA was significantly reduced in neurons pretreated with CXCL12. As expected,
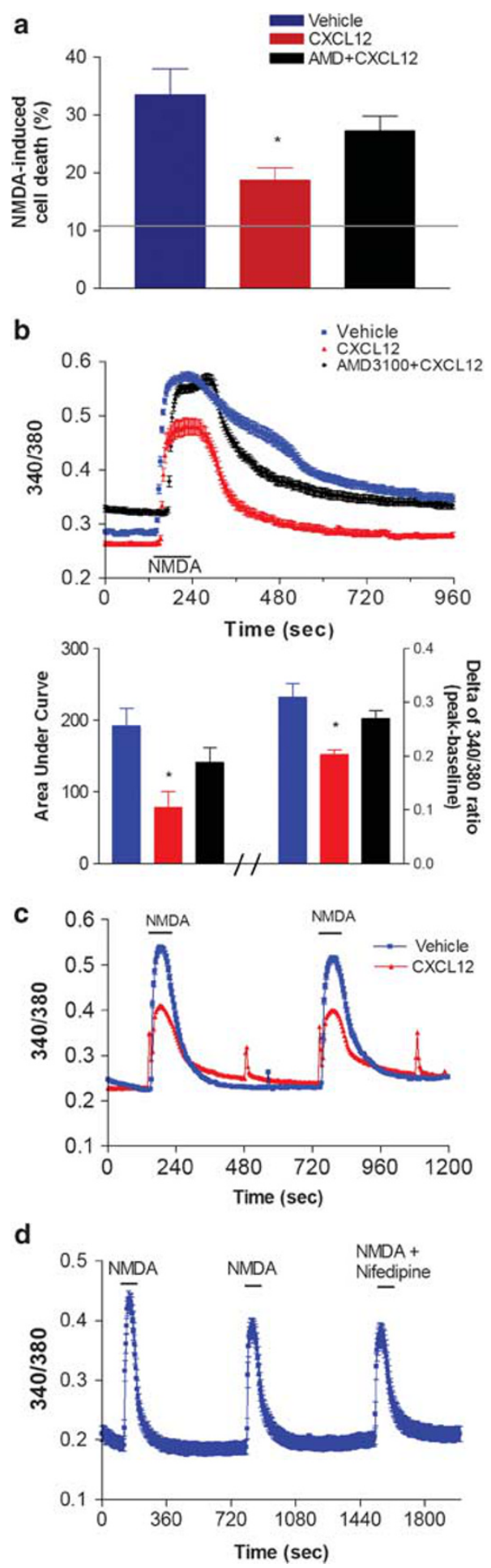
the CXCR4 antagonist AMD3100 significantly reduced the neuroprotective action of CXCL12 (Figure 1a and Supplementary Figure 1), in line with our previous report. ${ }^{19}$ These data indicate that stimulation of neuronal CXCR4 by CXCL12 induces long-term cellular changes that protect neurons from future excitotoxic insults.

Changes in intracellular calcium levels $\left(\left[\mathrm{Ca}^{+2}\right]_{\mathrm{i}}\right)$ represent a major event in determining the outcome of NMDA receptor stimulation on neurons, as they dictate the nature of downstream signaling leading to survival or excitotoxicity. ${ }^{6}$ Thus, we examined the effects of CXCL12 pretreatment on NMDA-induced $\left[\mathrm{Ca}^{+2}\right]_{i}$ changes in cortical neurons by using fura-2-based single cell imaging. As previously reported, ${ }^{22}$ a bath application of NMDA $(50-100 \mu \mathrm{M})$ induces large calcium responses in neurons indicated by an increase in the fura-2 fluorescence ratio (340/380) (Figure 1b). Changes in NMDAinduced $\left[\mathrm{Ca}^{+2}\right]_{i}$ were quantified by measuring both peak responses and area under the tracings. Figure $1 \mathrm{~b}$ shows that pre-exposure of neurons to CXCL12 significantly reduces the calcium rise evoked by NMDA. This effect of CXCL12 is blocked by cotreatment with AMD3100, suggesting that CXCR4 stimulation may regulate NMDA receptor function (Figure 1b). However, recent studies have suggested that short-term CXCL12 treatment can modulate voltage-sensitive calcium channels under specific conditions. ${ }^{23}$ Therefore, to establish whether this effect may contribute to the CXCL12 inhibition of NMDA-induced calcium response, the L-type calcium channel blocker nifedipine was used. The results of these experiments show that only a small portion $(\sim 10 \%)$ of the NMDA-induced calcium rise can be attributed to activation of voltage-sensitive calcium channels (Figure 1c and d), as also reported by others. ${ }^{24}$ Thus, the effect of CXCL12 is likely due to inhibition of the NMDA receptor. This conclusion was confirmed by additional studies (Supplementary Figure 2) showing that CXCL12 pretreatment does not inhibit the $\left[\mathrm{Ca}^{+2}\right]_{i}$ increase mediated by activation of voltage-sensitive calcium channel, after exposure of neurons to high concentrations of extracellular potassium $(\mathrm{KCl} 25 \mathrm{mM})$.

CXCL12 downregulates NR2B subunit of the NMDA receptor. Relative expression of $N R 2 B$ is one of the factors that contribute to calcium influx through NMDA receptors. ${ }^{25}$ Therefore, we sought to determine whether CXCL12 could alter levels of NR2B in neurons. To answer this question, we first measured total protein levels of NR2B after treatment of neurons with CXCL12 for increasing time periods (1-24h). As shown in Figure 2a and b, levels of NR2B protein in CXCL12-treated neurons decreased in a time- and AMD3100-dependent manner with significant changes becoming apparent after at least $3 \mathrm{~h}$. No changes in NR2A or NR1 protein levels are observed with the addition of CXCL12 and/or AMD3100 (Supplementary Figure 3a). Interestingly, CXCL12 also downregulates NR2B protein in human neuronal cells (Supplementary Figure 3b). Next, reverse transcriptase PCR (RT-PCR) was used to investigate the effect of CXCL12 on mRNA levels of different NMDA receptor subunits (Figure $2 \mathrm{c}$ ). To better evaluate the effect of CXCL12 on the specific subunits, amplification of each subunit was performed with concurrent amplification of the housekeeping gene Aldolase $A$. As shown in Figure 2c, treatment of rat cortical neurons with $C X C L 12$ reduces levels of $N R 2 B$ transcripts but not of $N R 1$ or $N R 2 A$. To further confirm and quantify this result, quantitative real-time PCR was performed (Figure 2d). As expected, stimulation with CXCL12 significantly decreased the mRNA levels of NR2B and no changes were observed in the NR1 subunit mRNA levels (Figure 2d). Overall, these results show that activation of the chemokine receptor by CXCL12 specifically decreases expression of the NR2B subunit of the NMDA receptor in post-mitotic neurons.

HDAC inhibitors prevent CXCL12 action. Our previous study has shown that CXCL12 stimulates the generepression activity of $\mathrm{Rb}$ in neurons, and that this protein is required for the neuroprotective role of $C X C L 12$ against NMDA toxicity. ${ }^{19}$ Importantly, $\mathrm{Rb}$ is involved in the neuronspecific repression complex calcium-responsive transactivation (CREST)-BRG1 that regulates activity-dependent expression of the $N R 2 B$ gene in cortical neurons. ${ }^{21}$ In particular, transcriptional repression of NR2B involves $\mathrm{Rb}$-dependent, BRG1-mediated recruitment of HDAC1 to the NR2B promoter. ${ }^{21}$ HDAC enzymes remove acetyl groups from histone tails, thus altering histone/DNA interactions and generally inhibiting gene transcription. ${ }^{26}$ Given the reported effect of CXCL12 on $\mathrm{Rb},{ }^{19}$ this implies that the action of CXCL12 on NR2B would depend on HDAC. To investigate this hypothesis, we first examined the effect of CXCL12 on histone acetylation by measuring levels of acetylated histone H3 (Figure 3a). As expected, CXCL12 reduced the levels of acetylated histone in treated neurons, suggesting that the chemokine positively regulates HDAC; in line with this result, the broad-spectrum HDAC inhibitor Trichostatin A (TSA) increased histone acetylation in sister cultures (Figure $3 a$ ). Next, we examined the effect of CXCL12 on NR2B protein levels in the presence of TSA and found that the downregulation of the NR2B subunit by CXCL12 was blocked by cotreatment of neurons with the HDAC inhibitor (Figure 3b). The effect of CXCL12 on the NMDA-induced calcium rise was also blocked by cotreatment with TSA (Figure 3c). Similar results were obtained with another, structurally unrelated, HDAC inhibitor, that is, sodium butyrate (Supplementary Figure 4), which exhibits a different mechanism of action compared with TSA. Overall, these data support the notion that regulation of NR2B by $\mathrm{CXCL} 12$ is mediated by physiological mechanisms involved in transcriptional repression of the NR2B gene, such as the CREST-BRG1 complex.

In vivo inhibition of CXCR4 increases NR2B protein levels. Our next goal was to determine whether CXCL12/ CXCR4 activity in vivo regulates levels of NR2B subunit in a similar manner to experiments conducted in neuronal cultures. To this end, lactating mothers were administered AMD3100 for four consecutive days, and the brains of pups were collected $6 \mathrm{~h}$ after the last treatment with the CXCR4 antagonist. To determine whether CXCR4 was effectively blocked in the brains of AMD-treated animals, two different approaches were used. First, CXCL12-induced G-protein activation was measured in the brain of control and AMD3100-treated animals by in situ GTP $\gamma$ S incorporation and autoradiography, as described previously. ${ }^{27}$ Second, 
a

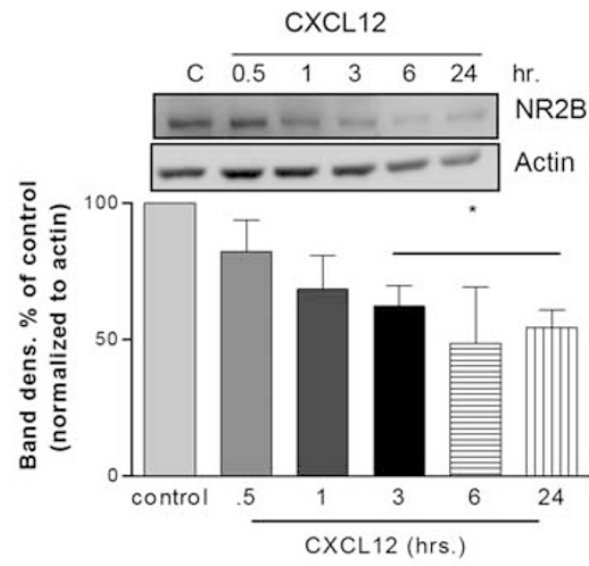

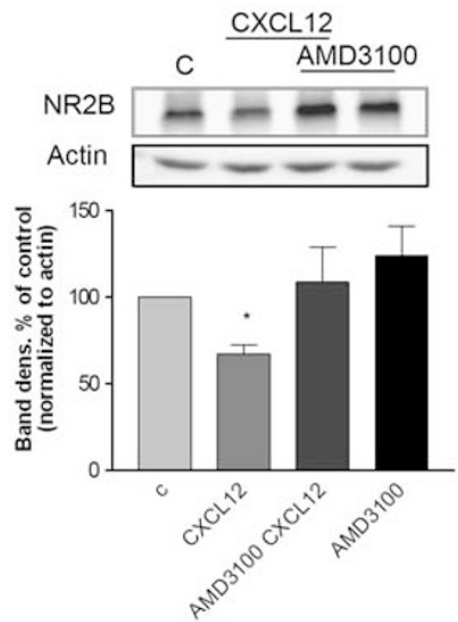
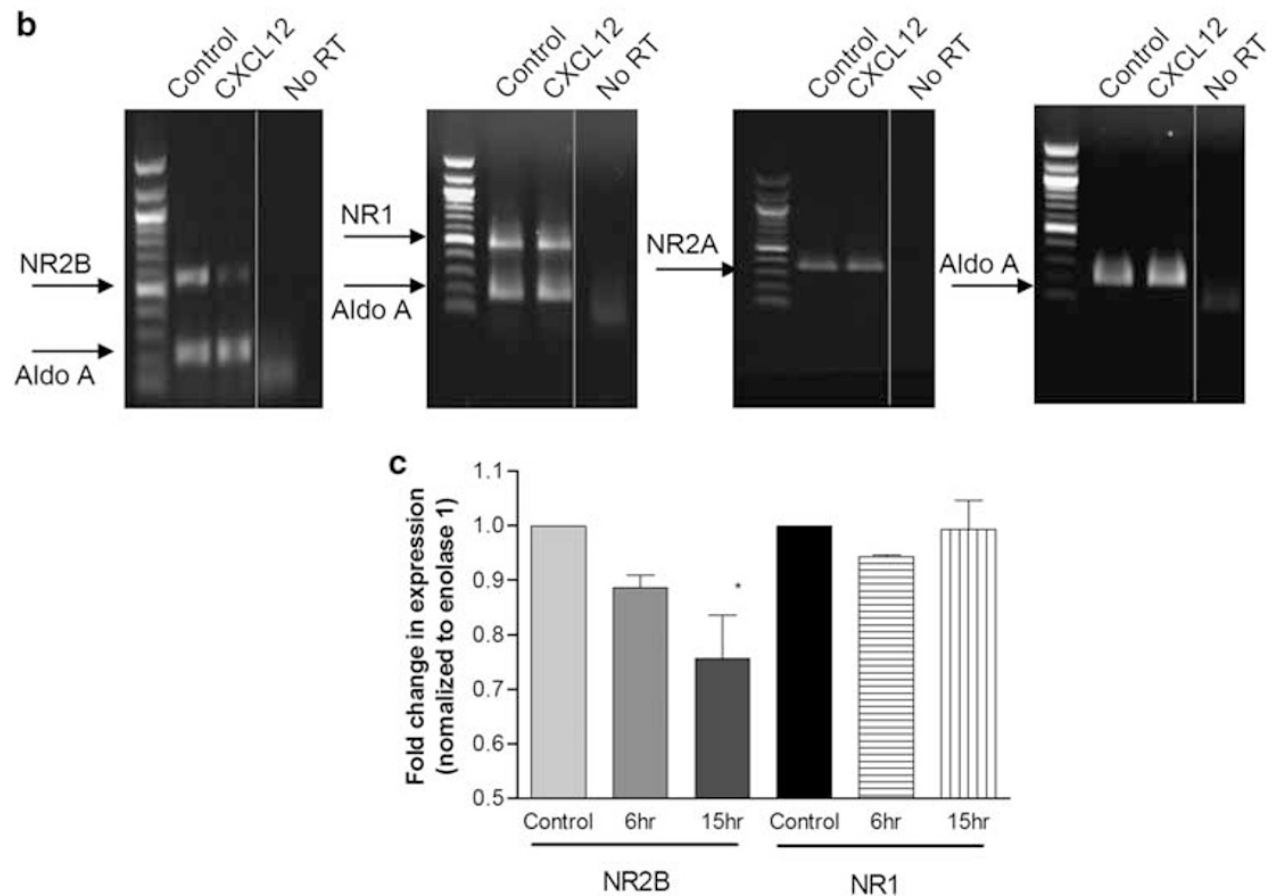

Figure 2 CXCL12 treatment reduces levels of NR2B protein and mRNA but does not alter other NMDA subunits. (a) Addition of CXCL12 (20 nM, 1-24h) to neuronal culture media decreases NR2B protein levels in a time-dependent manner. Graph shows data from three independent experiments ( ${ }^{*} P<0.05 \mathrm{ANOVA} ; 3,6,24 \mathrm{~h}$ compared with control) (b) The CXCR4 antagonist AMD3100 (100 ng/ml; added to cultures 20 min before CXCL12), blocked the effect of CXCL12 (20 nM) on NR2B protein levels. Bar graph reports data from four independent experiments ( ${ }^{\star} P<0.05$ ANOVA; $C X C L 12$ compared with all other groups). (c) mRNAs isolated from neuronal cultures treated with CXCL12 $(20 \mathrm{nM}, 6 \mathrm{~h}$ ) were analyzed by RT-PCR for NR2B, NR2A, or NR1 receptor levels. Separate gels were run for NR2A and AldoA because of close fragment lengths. (d) qPCR studies were performed on control and CXCL12-treated neurons. The graph indicates relative changes in NR2B and NR1 levels normalized to the housekeeping gene enolase $1\left({ }^{*} P<0.05\right.$ ANOVA; $15 \mathrm{~h}$ compared with control)

levels of the ligand-activated form of CXCR4, that is, CXCR4 phosphorylated on Ser339/8, ${ }^{28,29}$ were measured by immunohistochemistry and western blot in the brain of control and treated pups. The results show that AMD3100 treatment reduced both GTP 'binding' and pCXCR4 levels in the pups' brains (Figure 4a-c). Furthermore, the downregulation of CXCR4 function correlates with an increase in the NR2B protein, which was measured in brain tissue obtained from pups of the same litters (Figure 4d). These experiments suggest that stimulation of CXCR4 by its endogenous ligand controls levels of NR2B protein in vivo.
CXCL12-induced regulation of NR2B subunit contributes to neuronal survival through the modulation of extrasynaptic receptors. We used the NR2B-specific antagonist RO-256981 to determine whether the downregulation of the NR2B subunit by CXCL12 contributes to cell survival (Figure 5a). RO-256981 displays high affinity and specificity for NR2B-containing receptors with a maximal effective concentration of $10 \mu \mathrm{M} .{ }^{30}$ It was chosen over ifenprodil because of ifenprodil's possible nonspecific effects involving interactions with other receptors or ion channels. ${ }^{30}$ In line with previous studies, 
RO-256981 reduces cell death induced by NMDA, signifying a role for NR2B in NMDA excitotoxicity; this effect was comparable with CXCL12 neuroprotection (Figure 5a).
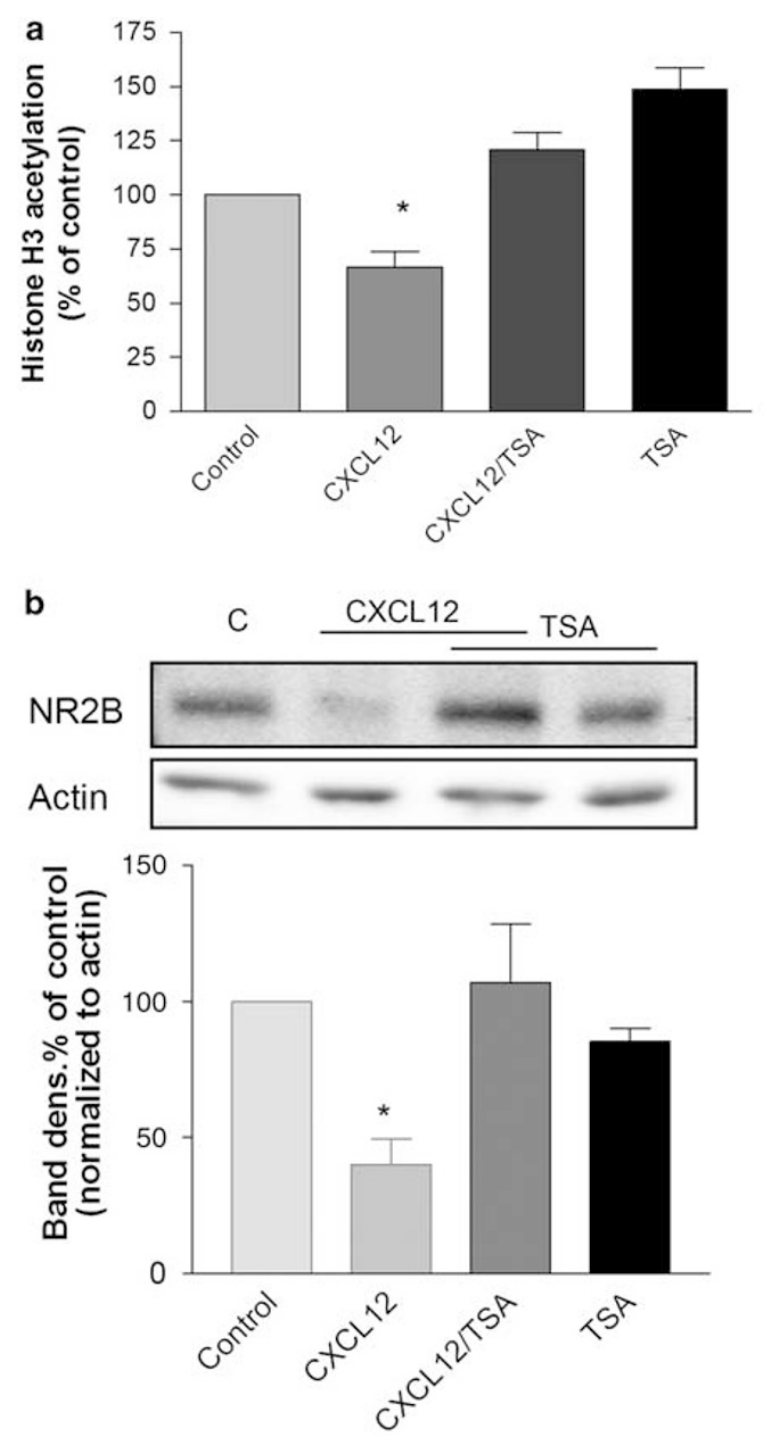

c

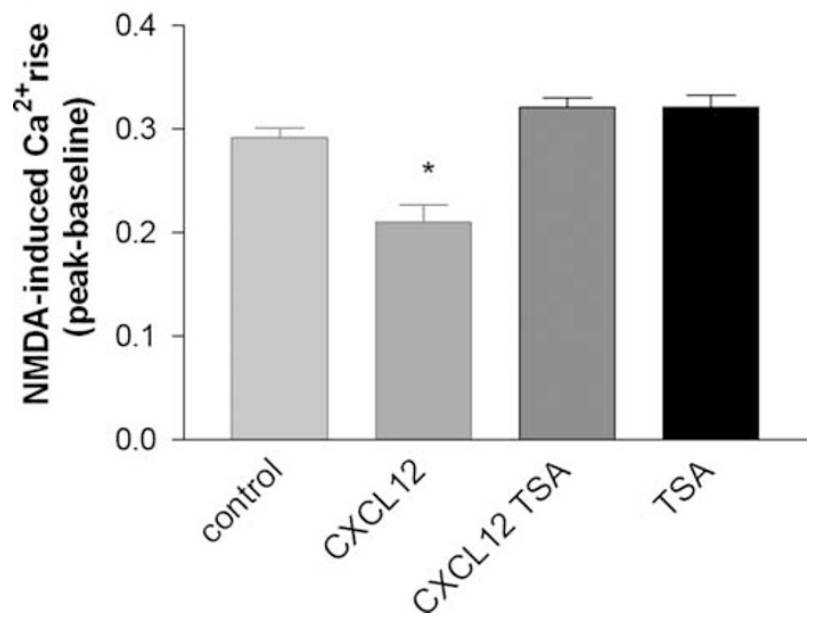

Similar results were obtained in neurons cotreated with RO-256981/CXCL12 (Figure 5a). As expected, on the basis of previous studies, ${ }^{30}$ RO-256981 blocks the majority of NMDA-induced calcium increase owing to its massive action on NR2B-containing receptors, whereas the partial reduction in NR2B protein levels caused by CXCL12 treatment leads to less robust reduction in the NMDA-induced calcium rise (Figure 5b). These data suggest that the reduction in NR2B function has a role in CXCL12-mediated neuroprotection. Furthermore, RO-256981 reduces NMDA calcium response to a similar extent in control and CXCL12-treated neurons (Figure 5b). Overall, these findings indicate that reduction in NR2B-containing receptors by CXCL12 significantly affects NMDA-induced calcium signaling, thus contributing to neuronal survival.

Several reports have indicated that overactivation of NR2B containing NMDA receptors located extrasynaptically may have a greater contribution to neurotoxicity. ${ }^{13,31} \mathrm{~A}$ high proportion of extrasynaptic NMDA receptors have been reported to contain NR2B subunits, and the activation of these receptors is associated with an increase in cell mortality; therefore, we next investigated the possibility that the neuroprotective effect of CXCL12 could be associated specifically with the regulation of extrasynaptic NR2B-containing receptors. To determine whether the downregulation of the NR2B subunit contributes to extrasynaptic or synaptic signaling, we used a well-characterized pharmacological approach to record each response independently as previously reported by others. ${ }^{11}$ This protocol takes advantage of the presence of GABAergic neurons that provide an inhibitory tone to the culture system. Bicuculline, a $G_{A B A}$ blocker, inhibits the intrinsic inhibitory synaptic GABA signaling inducing a physiological release of glutamate that in turn activates synaptic receptors. Bicuculline applied with 4-aminopyridine (4-AP), a weak potassium channel blocker, evokes transient calcium increases initiated by endogenous glutamate-activating synaptic receptors. ${ }^{13}$ The first calcium response in Figure $6 \mathrm{a}$ illustrates the synaptic calcium response induced by this protocol in control or CXCL12treated neurons. Selective activation of extrasynaptic receptors is achieved by first blocking the synaptic response with a coapplication of bicuculline/4-AP and the NMDA open channel blocker MK801. Application of bicuculline/4AP with MK801 ensures the selective blockage of the open synaptic

Figure $3 \mathrm{CXCL} 12$ reduces global histone $\mathrm{H} 3$ acetylation in neurons, and histone deacetylase (HDAC) inhibitors prevent the effects of CXCL12 on the NR2B. (a) Global $\mathrm{H} 3$ acetylation levels were measured through a colorimetric acetylation assay as indicated in the 'Materials and methods' section. Reduced levels of histone acetylation were found in CXCL12-treated ( $20 \mathrm{nM})$ neurons compared with control; this effect is blocked by cotreatment with TSA $(100 \mathrm{nM})\left({ }^{*} P<0.05\right.$ ANOVA; CXCL12 compared with all other groups) (b) Changes in NR2B protein levels in CXCL12- and/or TSA-treated neurons were analyzed by western blot. CXCL12 $(20 \mathrm{nM})$ and/or TSA ( $100 \mathrm{nM})$ were added to neuronal culture media for $24 \mathrm{~h}$; the bar graph reports the band density normalized to actin from three independent experiments ( ${ }^{*} P<0.05$ ANOVA; CXCL12 compared with all other groups). (c) Fura-2 studies indicate that TSA $(100 \mathrm{nM})$ treatment abolished the effect of CXCL12 $(20 \mathrm{nM})$ on NMDA-induced $(100 \mu \mathrm{M})$ calcium responses. Data in the bar graph are reported as changes in the $340 / 380$ ratios (i.e., from baseline to peak); at least 20 cells per treatment were analyzed from three independent experiments $\left({ }^{*} P<0.05\right.$ ANOVA; CXCL12 compared with all other groups) 
a
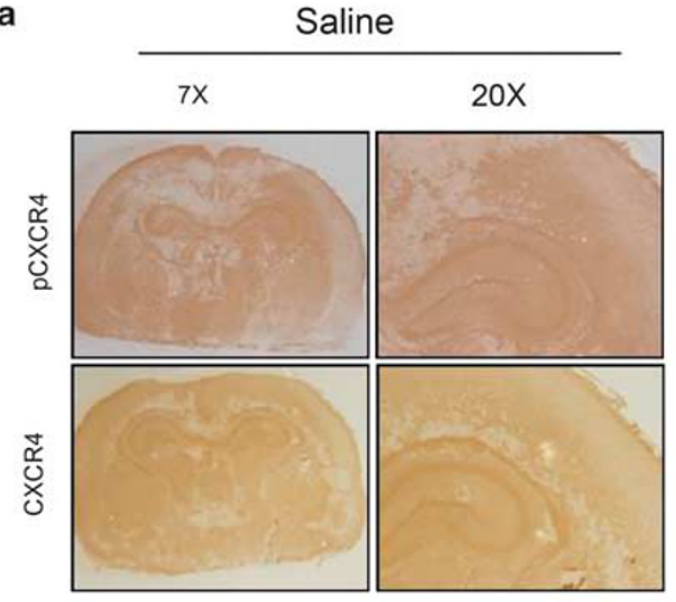

b
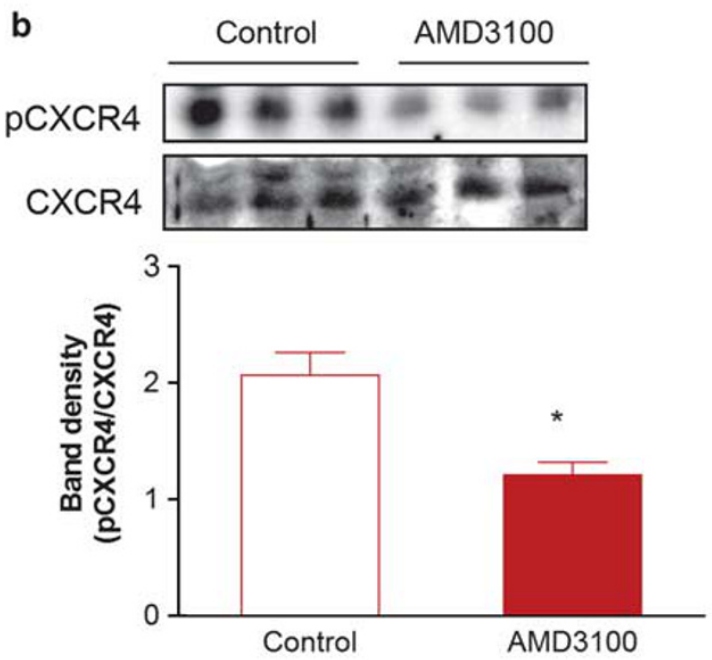

d

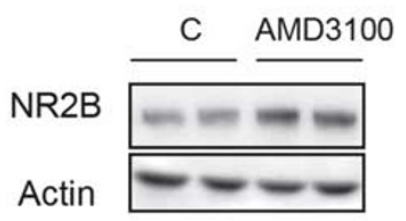

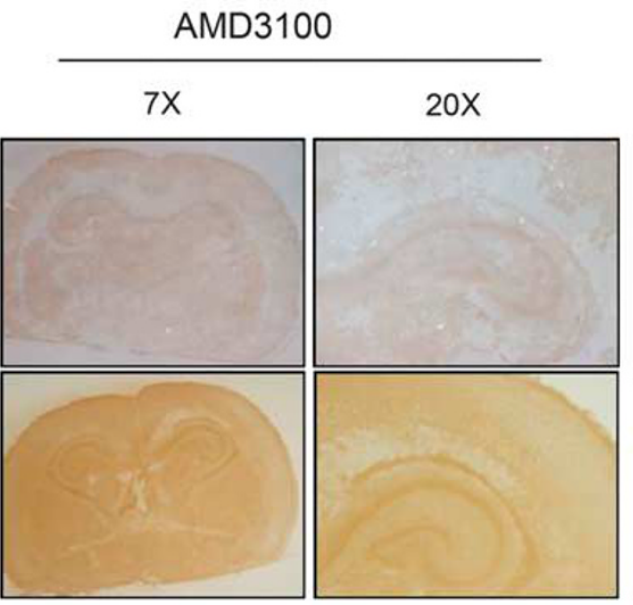

No Primary $A b$
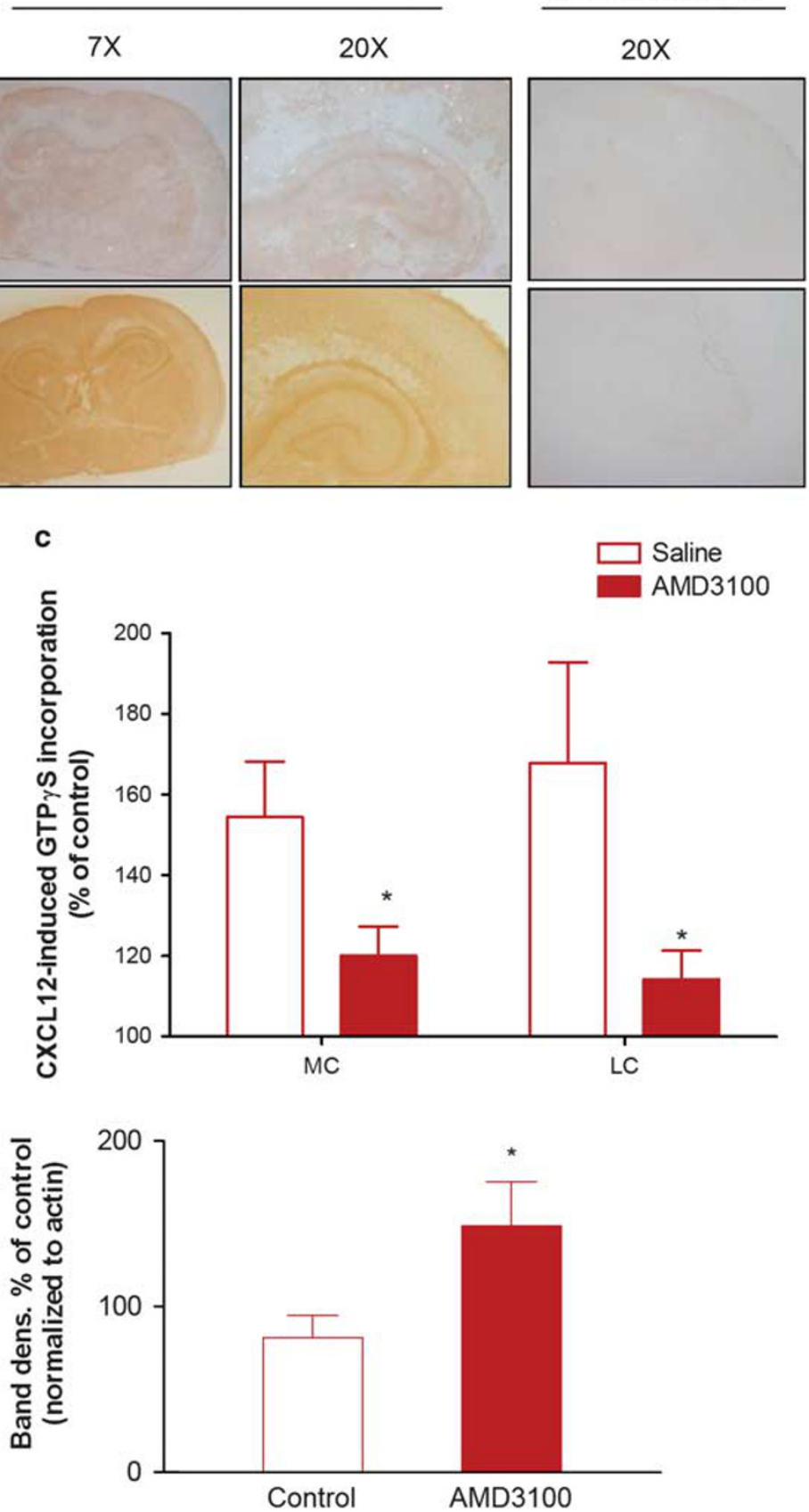

Figure 4 In vivo AMD3100 administration increases NR2B protein levels in the rat cortex. (a) AMD3100 treatment decreases CXCR4 phosphorylation in brain slices of treated animals as detected through immunohistochemistry, using phospho-specific antibodies against ligand-activated CXCR4. Three animals per group were analyzed and no changes were observed in total levels of CXCR4. (b) Studies in homogenized tissue samples (cerebral cortex and hippocampus) also show a reduction in phosphorylated levels of CXCR4 compared with total CXCR4 $\left({ }^{*} P<0.05\right.$ Student's $t$-test). The graph reports averaged data obtained from eight animals per group (representative immunoblot on the top). (c) AMD3100 pretreatment in vivo decreases $\left[{ }^{35} \mathrm{~S}\right] \mathrm{GTP} \gamma \mathrm{S}$ incorporation after stimulation of brain slices with CXCL12. Analysis was performed in different brain areas as previously reported: ${ }^{27}$ medial cortex (MC) and lateral cortex (LC). Three animals per treatment group were analyzed $\left({ }^{*} P<0.05\right.$ Student's $t$-test; AMD3100 compared with control in each brain region). (d) In vivo AMD3100 (1.25 mg/kg) treatment decreases NR2B protein levels in brain tissue (cerebral cortex and hippocampus) collected from P4 pups and analyzed by western blot. In all, 11 animals per treatment group were analyzed ( ${ }^{*} P<0.05$ Student's $t$-test)

receptors, which is illustrated by the second calcium response in Figure 6a. Finally, the extrasynaptic NMDA receptors are activated with a bath application of NMDA and depicted by the large calcium transient in the third part of Figure $6 a$. These paradigms were used to dissect the synaptic from the extrasynaptic calcium response. Neurons pretreated with CXCL12 exhibit a significant reduction in the extrasynaptic NMDA-induced calcium rise compared with control cells 


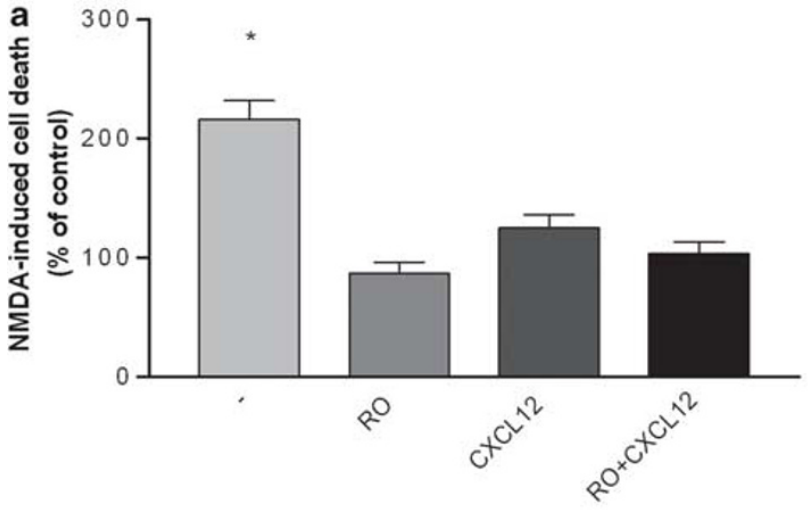

b

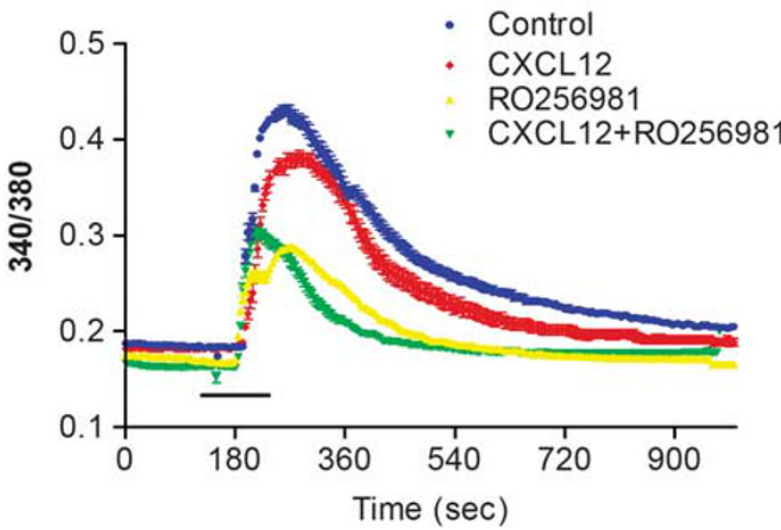

Figure 5 Effect of CXCL12 and RO-256981 on neuronal survival and NMDAinduced calcium changes. (a) CXCL12 $(20 \mathrm{nM}, 24 \mathrm{~h})$ and the NMDA antagonist RO-256981 $(10 \mu \mathrm{M}, 24 \mathrm{~h})$ independently protect neurons from NMDA treatment $\left({ }^{*} P<0.05\right.$ ANOVA; NMDA-treated compared with basal and all other treatment groups). (b) Calcium imaging studies show that RO-256981 markedly reduces NMDA-induced intracellular calcium rise both in control and CXCL12-treated neurons. The graph shows average calcium responses (mean \pm S.E.M.; $\sim 20$ cells per group)

(Figure 6b). Interestingly, CXCL12 also induces a small increase in the duration of the synaptic response but has no effect on the peak level of intracellular calcium elicited by the synaptic protocol (Figure $6 \mathrm{c}$ and d), indicating that CXCL12 does not impair calcium transients induced by activation of synaptic receptors. These data correlate with reports that extrasynaptic NMDA receptor activation has a greater contribution to excitotoxicity, and our hypothesis that CXCL12 promotes neuronal survival by reducing the presence of NR2B-containing receptors, which are mainly expressed at extrasynaptic levels in mature neurons. ${ }^{9,32,33}$

CXCR4 activation enhances synaptic signaling to the nucleus. Synaptic and extrasynaptic receptors seem to have distinct roles in neuronal survival in part by differentially activating signaling cascades. To study the effect of CXCL12 on survival signaling pathways stimulated by synaptic activation, we determined whether exposure to CXCL12 alters the extracellular-regulated kinase (ERK) response to NMDA. In neurons, ERK signaling mediates a key step in regulatory pathways involved in cell survival. ${ }^{34}$ Recent data indicate that NMDA receptor activation increases ERK phosphorylation exclusively by synaptic receptor activity. ${ }^{35}$ Furthermore, activation of extrasynaptic NMDA receptors containing NR2B subunits inactivates ERK by increasing the rate of dephosphorylation. ${ }^{15}$ Consistent with these findings, pretreatment of neurons with CXCL12 enhances ERK activation after bicuculline/4-AP treatment as compared with vehicle-treated neurons (Figure 7a). This is also in agreement with the effect of CXCL12 on synaptic/ extrasynaptic calcium responses (Figure 6), and suggests that the CXCL12 reduction of extra-synaptic NR2B receptors blocks ERK inactivation signal. In addition, CXCL12 may prolong NMDA synaptic activity, further promoting ERK phosphorylation as suggested by our previous calcium imaging results. Interestingly, activation of synaptic and extrasynaptic glutamate receptors leads to separate geneexpression profiles and synaptic receptor activation generally increases expression of prosurvival genes, including CXCR4. ${ }^{31}$ In line with these recent findings, we observe an increase in protein levels of CXCR4 following the synaptic activation protocol (Figure 7b). The ability of CXCL12 to regulate ERK activation and its downstream signaling triggered by the release of endogenous neurotransmitter indicates an important role of the chemokine in neuronal survival.

\section{Discussion}

CXCL12 and its receptor CXCR4 are expressed on neuronal and glial cells and control different processes involved in the development of the central nervous system (CNS) and inflammatory responses, such as cell migration and differentiation. Recent evidence has suggested that this chemokine/receptor pair may also contribute to homeostasis of the mature brain by regulation of cell survival and synaptic transmission. ${ }^{36,37}$ In line with this contention, in this study, we provide evidence of a novel mechanism that further implicates CXCL12 in the regulation of synaptic activity and neuronal signaling. Our results show that CXCL12/CXCR4 modulates the expression of NR2B, a critical subunit of the glutamate NMDA receptor, which is known to influence synaptic maturation, plasticity, and neuronal viability. Importantly, NR2B downregulation by CXCL12 is associated with a specific reduction in excitotoxic calcium responses and activation of extrasynaptic NMDA receptors; conversely, prosurvival responses coupled to stimulation of NMDA receptors located at the synaptic level seem to be facilitated by CXCL12, as shown by enhanced ERK activation following synaptic receptor activation in CXCL12-treated neurons. ERK signaling cascade is associated with spine formation, longterm potentiation, and neuronal survival. ${ }^{38}$ Recent studies have shown that ERK signaling is activated by synaptic NMDA receptors, and that stimulation of extrasynaptic receptors leads to ERK dephosphorylation/inactivation. ${ }^{15}$ CXCL12induced reduction in the extrasynaptic signal potentially blocks ERK dephosphorylation, which results in enhanced levels of pERK and cell survival. We also find that protein levels of CXCR4 are increased after synaptic NMDA receptor activation; this is relevant in view of the observation that synaptic activation upregulates functionally related genes contributing to neuronal survival. ${ }^{31}$ Therefore, 
a 1.

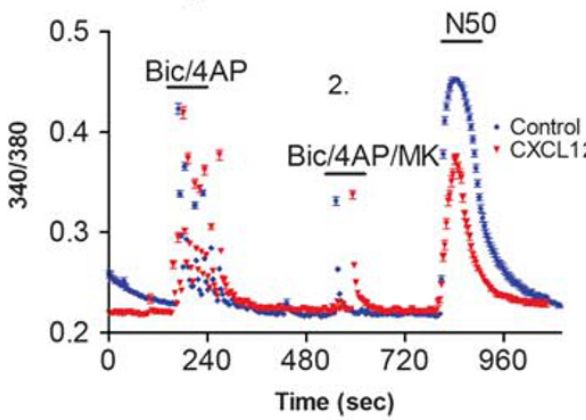

c

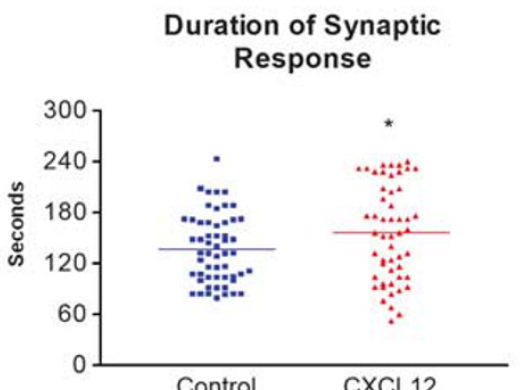

b

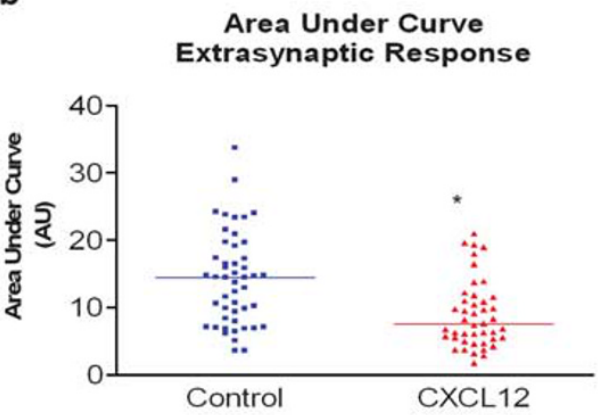

d

Peak Synaptic Response

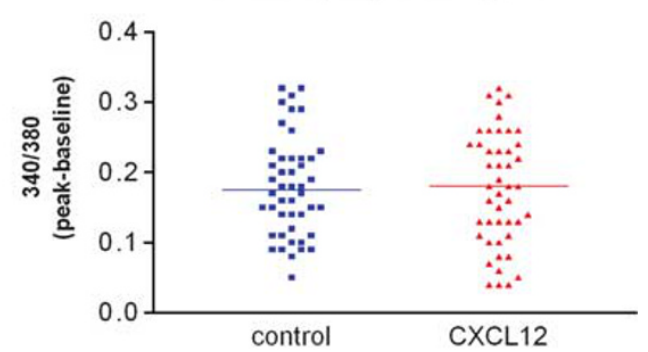

Figure 6 CXCL12 selectively decreases calcium responses induced by stimulation of NMDA extrasynaptic receptors. (a) Control neurons and CXCL12 pretreated neurons were stimulated with bicuculline $(50 \mu \mathrm{M})$ and 4-AP $(2.5 \mathrm{mM})$ to evoke a synaptic response, followed by a coapplication of bicuculline, 4-AP, and MK801 (10 $\mu \mathrm{M})$ to specifically and irreversibly block the synaptic NMDA receptors response. The following NMDA stimulation represents the extrasynaptic response induced by a bath application of NMDA $(50 \mu \mathrm{M})$. These experiments indicate a dramatic reduction in extrasynaptic response (graph b) and modest stimulation in synaptic responses (graphs $\mathbf{c}$ and $\mathbf{d})$. Data obtained from three or more independent experiments; a total of at least 45 neurons per group were studied $\left({ }^{*} P<0.05\right)$

a

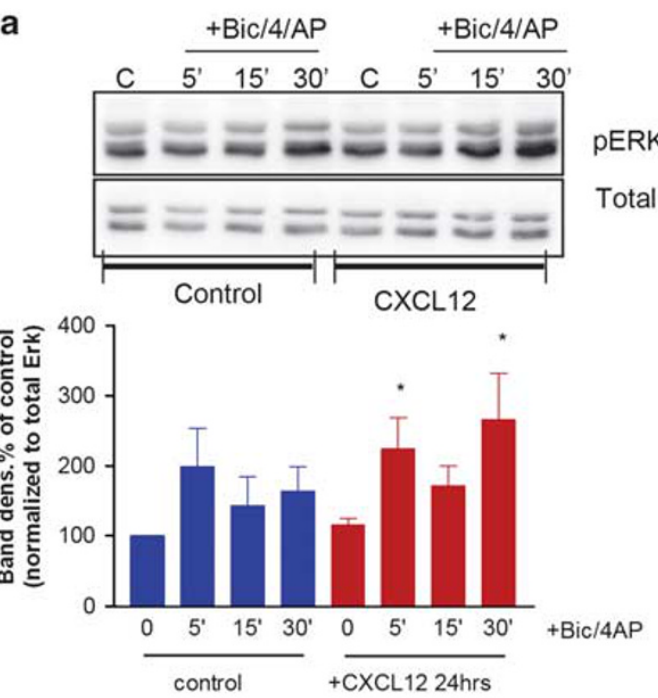

b
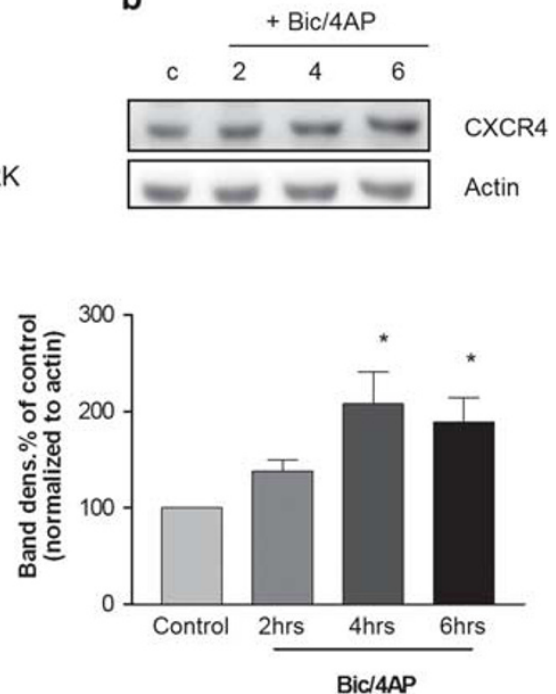

Figure 7 CXCL12 treatment enhances ERK activation stimulated by synaptic NMDA receptor activation. (a) Effect of CXCL12 on ERK activation after treatment with bicuculline and 4-AP, as reported above. Phospho-ERK immunoreactivity was normalized to total ERK, and the bar graph represents band density as a percentage of control from four independent experiments. ( ${ }^{*} P<0.05$ ANOVA; 5 and 15 min Bic/4AP-treated in CXCL12 group compared with control). (b) Selective activation of synaptic glutamate receptors by application of bicuculline and 4-AP for the indicated time increases CXCR4 protein levels in a time-dependent manner. Bar graph reports average data from three independent experiments ( ${ }^{*} P<0.05$ ANOVA; 4 and $6 \mathrm{~h}$ versus control)

CXCL12/CXCR4 may be involved in this positive feedback loop. Our data are also in agreement with reports showing predominant expression of NR2B at extrasynaptic sites in differentiated neurons $\mathrm{s}^{33}$ and the potential different contribution of NR2B- and NR2A-containing receptors to neurotoxicity. ${ }^{39}$ In addition, as during development NR2B is gradually 
replaced by NR2A at synaptic sites, CXCL12 may also contribute to synaptic maturation in developing neurons. However, further experiments are necessary to confirm the latter conclusion. Overall, our data show for the first time that CXCL12 induces long-term adaptive changes that ultimately modulate NMDA receptor functions. This hypothesis was initially suggested by our previous studies showing that CXCL12 positively regulates the gene repression (and neuroprotective) function of $\mathrm{Rb},{ }^{19}$ and is in agreement with the recently reported role of $\mathrm{Rb}$ and HDAC1 in the inhibition of NR2B expression by the CREST-BRG1 repressor complex. ${ }^{21}$ Thus, CXCL12-mediated regulation of NR2B expression contributes to the complex neurotrophic role of the chemokine in the CNS. Notably, the changes in NR2B levels observed in the brain of AMD-treated animals suggest that these mechanisms are also effective in vivo.

Given the role of HDAC in NR2B repression, we started investigating the potential of CXCL12 to act as an epigenetic modulator through regulation of histone-modifying enzymes, such as HDAC. Removing acetyl moieties from histone makes them more positively charged causing a greater association with the negatively charged DNA, which ultimately leads to gene repression. The data reported in this study show that CXCL12 decreases overall levels of acetylated histone H3, and ongoing studies suggest that the chemokine may regulate certain isoforms of HDAC (such as HDAC4) that shuttle from the cytosol to the nucleus depending on synaptic activity. If confirmed, these results would suggest that CXCL12 could alter the expression of a number of activity-dependent genes, which is currently under investigation by a separate study. The effects of TSA in terms of NR2B expression and NMDA-induced calcium changes are in apparent contrast with the reported neuroprotective action of general HDAC inhibitors. However, such neuroprotective action of HDACi has often been reported in the context of genetic disorders, suggesting that the effect of HDACi in these circumstances may be primarily related to the regulation of mutated/altered genes, with recovery of the normal phenotype. Moreover, HDACi may regulate specific survival genes, such as $p 21,{ }^{40}$ which would result in different outcomes depending on the involvement of such genes in the injury model. Indeed, neurotoxic effects of broad-spectrum HDAC inhibitors have also been reported, ${ }^{40,41}$ and little is known about the consequences of prolonged inhibition of HDAC. It is becoming more and more clear that potential long-term side effects of general HDAC inhibition may limit therapeutic tolerance, and a better understanding of specific gene regulation by epigenetic modulators is required. Finally, contributions of specific HDAC isoforms to neuronal survival, their regulation by neurotrophins, and the role of additional histone/DNA modifications will have to be established to generate more effective therapeutics. Thus, future combined efforts are required to fully address these issues.

In conclusion, this study provides the first evidence that CXCL12 affects NMDA receptors by regulating expression of the NR2B subunit - which has important implications to neuronal signaling and plasticity in both developing and mature neurons, and is highly relevant to a large spectrum of neurological disorders. This study and our previous findings ${ }^{19}$ collectively suggest that the effect of CXCL12 on NR2B involves physiological mechanisms of gene repression ${ }^{21}$ that are currently been exploited for therapeutic purposes, emphasizing the impact of this research in different fields.

\section{Materials and Methods}

Cell culture. Primary neurons were obtained from the cerebral cortex of embryonic day 17 (E17)/E18 rat embryos and cultured in the Neurobasal medium as reported previously. ${ }^{28}$ To further reduce the growth of non-neuronal cells, cytosine arabinoside $(1 \mu \mathrm{M})$ was added to the cultures. This leads to a virtually glia-free culture ( $>95 \%$ neurons) as assessed by expression of neuronal and non-neuronal markers. ${ }^{28}$ Briefly, neurons were plated at a density of 900000 cells per well of a 6-well plate in the Neurobasal medium containing B27 (2\%) and horse serum (2\%). The medium was replaced $2 \mathrm{~h}$ after plating with serum-free Neurobasal medium supplemented with B27, L-glutamine $(0.5 \mathrm{mM})$, glutamic acid $(25 \mu \mathrm{M})$ (Tocris Bioscience), and $10 \mu \mathrm{g} / \mathrm{ml}$ gentamycin. On the fourth and eighth day in vitro (DIV), the culture medium was replaced again with the Neurobasal media supplemented with B27, L-glutamine, and gentamycin. On the fourteenth day of culture, half of the media were changed with the Neurobasal media supplemented with B27, L-glutamine, and gentamycin. Neurons were used between DIV 16 and 20. Human neuronal cell line, SH-SY5Y, was acquired from the ATCC. Cells were cultured in media containing 10\% FBS, 45\% MEM, and $45 \% \mathrm{~F}-12$. Culture media were changed every 3 days and cells were split when they reached $\sim 85 \%$ confluency.

Western blots. Primary neurons were washed with ice-cold phosphatebuffered saline (PBS), collected in lysis buffer $(150 \mathrm{mM} \mathrm{NaCl}, 50 \mathrm{mM}$ Tris, $0.5 \% \mathrm{Na}$ deoxycholate, $0.1 \%$ SDS, $10 \mathrm{mM} \mathrm{Na}_{4} \mathrm{P}_{2} \mathrm{O}_{7}, 5 \mathrm{mM}$ EDTA, $1 \%$ Triton X-100, and protease and phosphatase inhibitor mixture), and then incubated for $30 \mathrm{~min}$ at $4{ }^{\circ} \mathrm{C}$ as reported previously. ${ }^{19,20,28}$ Lysates were spun (14000 r.p.m. for $10 \mathrm{~min}$ ) in an Eppendorf 5417R microcentrifuge, and the protein concentration of the supernatants was determined using bicinchoninic acid protein assay following the instructions of the manufacturer (Pierce). Equal amounts of protein (20 $\mu \mathrm{g}$ per lane) were loaded for SDS-PAGE, followed by immunoblotting. The following antibodies were used: anti-NR2B (1:1000) (R\&D, Alomone), anti-actin (1:1000) (SigmaAldrich), anti-pERK (1: 1000), and total ERK (1:1000) (Cell Signaling Technology). Bands were detected by Pierce chemiluminescence reagents (SuperSignal West Femto maximum sensitivity) and analyzed using the image detection and analysis system from Alpha Innotech, FluorChem 8900 (San Leandro, CA, USA). Values from actin or total ERK were used to verify equal loading and for normalization. Brain tissue homogenates (the cortex and hippocampus) were washed once with PBS and incubated in lysis buffer on ice for $20 \mathrm{~min}$, followed by centrifugation at 28000 for $20 \mathrm{~min}$. The protein concentration was measured and equal amounts of protein were used for SDS-PAGE, followed by immunoblotting with antibodies against pCXCR4 S339 (1:1000), ${ }^{29}$ CXCR4 (1:1000; Abcam), and NR2B (1: 1000 Alomone).

Survival assays. Neurons were plated on glass coverslips ( $15 \mathrm{~mm}$ diameter) at a density of 35000 cells per coverslip. CXCL12 (20 nM) was added to neuronal culture medium for $24 \mathrm{~h}$ and then washed with PBS solution. Neurons were returned to a magnesium-free saline solution ( $157 \mathrm{mM} \mathrm{NaCl}, 5 \mathrm{mM} \mathrm{KCl}, 0.64 \mathrm{KH}_{2} \mathrm{PO}_{4}, 3 \mathrm{mM}$ $\mathrm{NaHCO}_{3}, 5 \mathrm{mM}$ glucose, $20 \mathrm{mM}$ HEPES, $0.33 \mathrm{mM} \mathrm{Na}_{2} \mathrm{HPO}_{4}$ ) containing $2 \mathrm{mM}$ $\mathrm{CaCl}_{2}$ and treated with NMDA for 20 min. Cells were washed again with PBS and fresh culture media were added. Survival was assayed $24 \mathrm{~h}$ after NMDA treatment with a combination of propidium iodine $(10 \mu \mathrm{m} / \mathrm{ml} /$ fluorescein diacetate $(10 \mu \mathrm{g} / \mathrm{ml}) /$ Hoescht 3342 staining $(5 \mu \mathrm{g} / \mathrm{ml})$ as reported previously. ${ }^{19,20}$ Ten random fields per coverslip and three coverslips per treatment were analyzed for each independent experiment. Results are expressed as a percentage of dead cells. Approximately 200 cells per treatment group were used.

Calcium imaging. Neurons plated on glass coverslips $(15 \mathrm{~mm})$ and cultured as described above were loaded with $2 \mu \mathrm{M}$ fura-2 AM (Molecular Probes) for $20 \mathrm{~min}$ (r.t.), washed with saline solution $\left(157 \mathrm{mM} \mathrm{NaCl}, 5 \mathrm{mM} \mathrm{KCl}, 0.4 \mathrm{mM} \mathrm{MgSO}_{4}\right.$ $0.5 \mathrm{mM} \mathrm{MgCl}, 0.64 \mathrm{KH}_{2} \mathrm{PO}_{4}, 3 \mathrm{mM} \mathrm{NaHCO}, 5 \mathrm{mM}$ glucose, $20 \mathrm{mM}$ HEPES, $0.33 \mathrm{mM} \mathrm{Na}_{2} \mathrm{HPO}_{4}, 2 \mathrm{mM} \mathrm{CaCl}$ ) and re-incubated for an additional $20 \mathrm{~min}$ at room temperature as described previously. ${ }^{22}$ During the experiments, cells were perfused with an external magnesium-free saline solution $(157 \mathrm{mM} \mathrm{NaCl}, 5 \mathrm{mM}$ $\mathrm{KCl}, 0.64 \mathrm{KH}_{2} \mathrm{PO}_{4}, 3 \mathrm{mM} \mathrm{NaHCO}, 5 \mathrm{mM}$ glucose, $20 \mathrm{mM}$ HEPES, $0.33 \mathrm{mM}$ $\mathrm{Na}_{2} \mathrm{HPO}_{4}$ ) containing $2 \mathrm{mM} \mathrm{CaCl}$. Each cell in the field was analyzed 
independently. NMDA-induced calcium rises recorded from individual cells were quantified by peak responses (calculated as the difference between peak response and pre-stimulus baseline) and area under the traces. Extrasynaptic and synaptic responses were isolated following a protocol published by Leveille et al. (2008). Briefly, synaptic responses were evoked with the application of bicuculline $(50 \mu \mathrm{M})$ and 4-AP $(2.5 \mathrm{mM})$, whereas extrasynaptic responses were isolated through blocking the synaptic response with MK801 $(10 \mu \mathrm{M})$ in addition to bicuculline and 4-AP. The following NMDA stimulation evoked the extrasynaptic NMDA response.

RNA extraction and RT-PCR. Total RNA was extracted using the RNeasy mini kit (Qiagen) as reported previously. ${ }^{19,20}$ The RNA quality and concentration were assessed using the NanoDrop ND-1000 spectrophotometer (NanoDrop Technologies). Samples with optical density $260 / 280$ and $260 / 230$ ratios of $\geqslant 1.8$ were used for PCR studies. Random hexamers were used to synthesize cDNAs. The following primers were used to amplify NR2B, NR1, or Aldolase A: NR2B, 5'-GGATCTACCAGTCTAACATG-3' and 5'-GATAGTTAGTGATCCCACTG-3'; NR1, $5^{\prime}$-TACACTGCCAACTTGGCAGCTTTC- $3^{\prime}$ and $5^{\prime}$-CATGAAGACCCCTGC CATGTT-3'. For rat Aldolase A, the following primers were used: $5^{\prime}$-AACCAATG GCGAGACCACTAC-3' and 5'-AATTTCAGGCTCCACAATGG-3'

qPCR. Total RNA was isolated from control or CXCL12 $(20 \mathrm{nM})$-treated primary rat cortical neurons. CDNA was synthesized as mentioned above. Amplification was performed with Taqman PCR master mix (Applied Biosystems, Foster City, CA, USA) on ABI PRISM 7300 Sequence detection system (Applied Biosystems) as reported in Khan et al. (2008). Briefly, the thermal cycle profile for all transcripts was as follows (the reaction initiated at $95^{\circ} \mathrm{C}$ for $15 \mathrm{~min}$ ). A total of $40 \mathrm{PCR}$ cycles were performed with $30 \mathrm{~s}$ of denaturing at $95^{\circ} \mathrm{C}$ then $30 \mathrm{~s}$ at $55^{\circ} \mathrm{C}$ for annealing and $30 \mathrm{~s}$ at $72^{\circ} \mathrm{C}$ for extension. After amplification, a melting-curve analysis of the amplified DNA was performed. A standard curve for each gene was generated to determine the linear range and amplification efficiency. The $\Lambda \Lambda \mathrm{CT}$ method was used to analyze the data. Levels of NR1 or NR2B were expressed relative to fold change after normalization to that of the housekeeping gene Enolase. Real-time PCR quantification was performed in triplicate from three separate experiments.

Histone acetylation assay. Histone $\mathrm{H} 3$ acetylation was measured using the EpiQuick Global Histone H3 acetylation assay kit following the manufacturer's instructions (Epigentek). Briefly, nucleic fraction was isolated and histones were extracted from cell lysates. Histone proteins were then stably spotted on microplate strip wells by incubating wells at $37^{\circ} \mathrm{C}$ for $90 \mathrm{~min}$. The primary antibody to detect acetylated histone was incubated for $1 \mathrm{~h}$ at room temperature. The amount of aceylated histone was detected by HRP-conjugated secondary antibody and quantified through a colorimetric reaction by the microplate reader.

In vivo AMD3100 Administration and GTP $\gamma$ S Autoradiography. AMD3100 (Sigma-Aldrich) was dissolved in physiological saline (PBS) and injected intraperitoneally (IP) $1.25 \mathrm{mg} / \mathrm{kg}$ to lactating Holtzmann rat beginning 1 day after giving birth. The lactating mother was injected one time per day for four consecutive days. Rat pups postnatal days 5 (P5) were killed $6 \mathrm{~h}$ after the last injection to the mother. The brains of the pups were rapidly removed, quickly frozen, and stored at $-80^{\circ} \mathrm{C}$. $\left[{ }^{35} \mathrm{~S}\right] \mathrm{GTP} \gamma \mathrm{S}$ autoradiography was performed on coronal sections as described previously. ${ }^{27}$ Briefly, 20- $\mu \mathrm{M}$ sections mounted onto slides were pre-incubated in slide mailers for $40 \mathrm{~min}$ at $25^{\circ} \mathrm{C}$ in assay buffer (in $\mathrm{mM}: 50$ Tris-HCl, $4 \mathrm{MgCl}_{2}, 0.3 \mathrm{EGTA}$, and $100 \mathrm{NaCl} ; \mathrm{pH} 7.4$ ), followed by 20 min incubation in $2 \mathrm{mM} \mathrm{GDP}$ in assay buffer. Sections were then incubated for $2 \mathrm{~h}$ at $25^{\circ} \mathrm{C}$ in assay buffer containing $\left.{ }^{35} \mathrm{~S}\right] \mathrm{GTP} \gamma \mathrm{S}(0.04 \mathrm{nM}, 1250 \mathrm{ci} / \mathrm{mmol})$ and $2 \mathrm{mM}$ GDP. After incubation, sliders were rinsed twice in cold Tris- $\mathrm{HCl}(50 \mathrm{mM})$ and then briefly in cold deionized water, dried immediately with a cool stream of air, and desiccated overnight. Slides were exposed to Kodak Biomax MS film (Eastman Kodak) for $48 \mathrm{~h}$. Images from the developed films were scanned and quantified using Image Pro-Plus Version 4.5 software (MediaCybernetics).

Immunohistochemistry. Immunohistochemical analysis was performed as described previously. ${ }^{20,28}$ Briefly, $20-\mu \mathrm{M}$ sections were stored at $-20^{\circ} \mathrm{C}$ for $24 \mathrm{~h}$ and then air dried at room temperature for $60 \mathrm{~min}$. Sections were then fixed for $2 \mathrm{~min}$ with acetone at room temperature. Before incubation with primary antibody, the sections were blocked in normal donkey serum, 1:250 diluted with $1 \times$ Trisbuffered saline (TBS, $\mathrm{pH} 7.4$ ). The sections were then incubated overnight with primary antibody pCXCR4 $(1: 50)$ and CXCR4 $(1: 50)$ diluted in $1 \times$ TBS with $2.5 \%$ normal donkey serum. After washing three times with $1 \times$ TBS, sections were incubated with HRP anti-rabbit secondary antibody (Jackson Immuno Research) and 1:250 diluted in $1 \times$ TBS with $2.5 \%$ normal donkey serum for $2 \mathrm{~h}$ at room temperature. Reaction products were visualized by the avidin-biotin peroxide complex method (Vector Laboratories). Negative controls were processed in a similar manner without the addition of the primary antibody.

Statistical analysis. Each graph reports the mean \pm S.E.M. of three to four independent experiments unless otherwise noted. Student's $t$-test or one-way ANOVA, followed by Newman-Keuls post hoc test were used for statistical analysis. A $P<0.05$ or less was considered significant.

\section{Conflict of interest}

The authors declare no conflict of interest.

Acknowledgements. This study was supported by $\mathrm{NIH}$ grants to $\mathrm{OM}$ (DA15014 and DA19808) and to JR (CA118389). We thank Saori Shimizu (DUCoM) for initial help with RT-PCR/qPCR studies and Alessandro Fatatis (DUCOM) for critical reading of the manuscript.

1. Kaul M, Lipton SA. Mechanisms of neuronal injury and death in HIV-1 associated dementia. Curr HIV Res 2006; 4: 307-318.

2. Greenwood SM, Connolly CN. Dendritic and mitochondrial changes during glutamate excitotoxicity. Neuropharmacology 2007; 53: 891-898.

3. Waxman EA, Lynch DR. N-methyl-D-aspartate receptor subtypes: multiple roles in excitotoxicity and neurological disease. Neuroscientist 2005; 11: 37-49.

4. Wollmuth LP, Sobolevsky Al. Structure and gating of the glutamate receptor ion channel. Trends Neurosci 2004; 27 : 321-328.

5. Burnashev N. Calcium permeability of glutamate-gated channels in the central nervous system. Curr Opin Neurobiol 1996; 6: 311-317.

6. Sattler R, Tymianski M. Molecular mechanisms of glutamate receptor-mediated excitotoxic neuronal cell death. Mol Neurobiol 2001; 24: 107-129.

7. Villmann $\mathrm{C}$, Becker $\mathrm{CM}$. On the hypes and falls in neuroprotection: targeting the NMDA receptor. Neuroscientist 2007; 13: 594-615.

8. Monyer H, Burnashev N, Laurie DJ, Sakmann B, Seeburg PH. Developmental and regional expression in the rat brain and functional properties of four NMDA receptors. Neuron 1994; 12: 529-540.

9. Tovar KR, Westbrook GL. Mobile NMDA receptors at hippocampal synapses. Neuron 2002; 34: 255-264.

10. Miwa H, Fukaya M, Watabe AM, Watanabe M, Manabe T. Functional contributions of synaptically localized NR2B subunits of the NMDA receptor to synaptic transmission and long-term potentiation in the adult mouse CNS. J Physiol 2008; 586: 2539-2550.

11. Leveille F, EI Gaamouch F, Gouix E, Lecocq M, Lobner D, Nicole O et al. Neuronal viability is controlled by a functional relation between synaptic and extrasynaptic NMDA receptors. FASEB J 2008; 22: 4258-4271.

12. Bading H, Ginty DD, Greenberg ME. Regulation of gene expression in hippocampal neurons by distinct calcium signaling pathways. Science 1993; 260: 181-186.

13. Hardingham GE, Fukunaga $Y$, Bading $H$. Extrasynaptic NMDARs oppose synaptic NMDARs by triggering CREB shut-off and cell death pathways. Nat Neurosci 2002; 5: 405-414.

14. Massey PV, Johnson BE, Moult PR, Auberson YP, Brown MW, Molnar E et al. Differential roles of NR2A and NR2B-containing NMDA receptors in cortical long-term potentiation and long-term depression. J Neurosci 2004; 24: 7821-7828.

15. Ivanov A, Pellegrino C, Rama S, Dumalska I, Salyha Y, Ben-Ari Y et al. Opposing role of synaptic and extrasynaptic NMDA receptors in regulation of the extracellular signalregulated kinases (ERK) activity in cultured rat hippocampal neurons. J Physiol 2006; 572 (Part 3): 789-798.

16. Li M, Ransohoff RM. Multiple roles of chemokine CXCL12 in the central nervous system: a migration from immunology to neurobiology. Prog Neurobiol 2008; 84: 116-131.

17. Bezzi $P$, Domercq M, Brambilla L, Galli R, Schols D, De Clercq E et al. CXCR4-activated astrocyte glutamate release via TNFalpha: amplification by microglia triggers neurotoxicity. Nat Neurosci 2001; 4: 702-710.

18. Bhattacharyya BJ, Banisadr G, Jung H, Ren D, Cronshaw DG, Zou Y et al. The chemokine stromal cell-derived factor-1 regulates GABAergic inputs to neural progenitors in the postnatal dentate gyrus. J Neurosci 2008; 28: 6720-6730.

19. Khan MZ, Brandimarti R, Shimizu S, Nicolai J, Crowe E, Meucci O. The chemokine CXCL12 promotes survival of postmitotic neurons by regulating Rb protein. Cell Death Differ 2008; 15: 1663-1672.

20. Shimizu S, Khan MZ, Hippensteel RL, Parkar A, Raghupathi R, Meucci O. Role of the transcription factor E2F1 in CXCR4-mediated neurotoxicity and HIV neuropathology. Neurobiol Dis 2007; 25: 17-26.

21. Qiu Z, Ghosh A. A calcium-dependent switch in a CREST-BRG1 complex regulates activity-dependent gene expression. Neuron 2008; 60: 775-787. 
22. Meucci O, Miller RJ. gp120-induced neurotoxicity in hippocampal pyramidal neuron cultures: protective action of TGF-beta1. J Neurosci 1996; 16: 4080-4088.

23. Oh SB, Endoh T, Simen AA, Ren D, Miller RJ. Regulation of calcium currents by chemokines and their receptors. J Neuroimmunol 2002; 123: 66-75.

24. Sattler R, Charlton MP, Hafner M, Tymianski M. Distinct influx pathways, not calcium load, determine neuronal vulnerability to calcium neurotoxicity. J Neurochem 1998; 71 2349-2364.

25. Papadia S, Hardingham GE. The dichotomy of NMDA receptor signaling. Neuroscientist 2007; 13: 572-579.

26. Saha RN, Pahan K. HATs and HDACs in neurodegeneration: a tale of disconcerted acetylation homeostasis. Cell Death Differ 2006; 13: 539-550.

27. Burbassi S, Aloyo VJ, Simansky KJ, Meucci O. GTPgammaS incorporation in the rat brain: a study on mu-opioid receptors and CXCR4. J Neuroimmune Pharmacol 2008; 3 : 26-34

28. Sengupta R, Burbassi S, Shimizu S, Cappello S, Vallee RB, Rubin JB et al. Morphine increases brain levels of ferritin heavy chain leading to inhibition of CXCR4-mediated survival signaling in neurons. J Neurosci 2009; 29: 2534-2544.

29. Woerner BM, Warrington NM, Kung AL, Perry A, Rubin JB. Widespread CXCR4 activation in astrocytomas revealed by phospho-CXCR4-specific antibodies. Cancer Res 2005; 65 11392-11399.

30. Lynch DR, Guttmann RP. NMDA receptor pharmacology: perspectives from molecular biology. Curr Drug Targets 2001; 2: 215-231.

31. Zhang SJ, Steijaert MN, Lau D, Schutz G, Delucinge-Vivier C, Descombes $P$ et al. Decoding NMDA receptor signaling: identification of genomic programs specifying neuronal survival and death. Neuron 2007; 53: 549-562.

32. Kim MJ, Dunah AW, Wang YT, Sheng M. Differential roles of NR2A- and NR2B-containing NMDA receptors in Ras-ERK signaling and AMPA receptor trafficking. Neuron 2005; 46 745-760.

33. Stocca G, Vicini S. Increased contribution of NR2A subunit to synaptic NMDA receptors in developing rat cortical neurons. J Physiol 1998; 507 (Part 1): 13-24.
34. Bonni A, Brunet A, West AE, Datta SR, Takasu MA, Greenberg ME. Cell survival promoted by the Ras-MAPK signaling pathway by transcription-dependent and -independent mechanisms. Science 1999; 286: 1358-1362.

35. Hardingham GE, Arnold FJ, Bading H. A calcium microdomain near NMDA receptors: on switch for ERK-dependent synapse-to-nucleus communication. Nat Neurosci 2001; 4 : 565-566.

36. Miller RJ, Rostene W, Apartis E, Banisadr G, Biber K, Milligan ED et al. Chemokine action in the nervous system. J Neurosci 2008; 28: 11792-11795.

37. Melik-Parsadaniantz S, Rostene W. Chemokines and neuromodulation. J Neuroimmunol 2008; 198: 62-68.

38. Thomas GM, Huganir RL. MAPK cascade signalling and synaptic plasticity. Nat Rev Neurosci 2004; 5: 173-183.

39. Liu Y, Wong TP, Aarts M, Rooyakkers A, Liu L, Lai TW et al. NMDA receptor subunits have differential roles in mediating excitotoxic neuronal death both in vitro and in vivo. J Neurosci 2007; 27: 2846-2857.

40. Langley B, D'Annibale MA, Suh K, Ayoub I, Tolhurst A, Bastan B et al. Pulse inhibition of histone deacetylases induces complete resistance to oxidative death in cortical neurons without toxicity and reveals a role for cytoplasmic p21(waf1/cip1) in cell cycle-independent neuroprotection. J Neurosci 2008; 28: 163-176.

41. Salminen A, Tapiola T, Korhonen P, Suuronen T. Neuronal apoptosis induced by histone deacetylase inhibitors. Brain Res Mol Brain Res 1998; 61: 203-206.

Cell Death and Disease is an open-access journal published by Nature Publishing Group. This article is licensed under a Creative Commons Attribution-Noncommercial-No Derivative Works 3.0 License. To view a copy of this license, visit http:// creativecommons.org/licenses/by-nc-nd/3.0/

Supplementary Information accompanies the paper on Cell Death and Disease website (http://www.nature.com/cddis) 